\title{
ق̈FFRSETI
}

Forseti. Revista de Derecho. Edición de aniversario, Lima, DERUP, 2018, pp 119-127

\section{El arbitraje y los procesos de la jurisdicción ordinaria}

\author{
Mario Castillo Freyre*
}

Resumen.- A través del presente artículo, se analizan las diferencias existentes entre el arbitraje y los procesos de la jurisdicción ordinaria, ya que si bien es cierto según la Constitución Política ambos son jurisdicción, también es verdad que existen rasgos que los hacen únicos y que pasan por la base legal que los sustenta, el momento en que se constituyen los tribunales, las normas que éstos aplican, el tipo de resoluciones que se emiten, las instancias que poseen, entre otros.

\begin{abstract}
By means of the following article, the existing differences between arbitration and the processes of ordinary jurisdiction are analyzed, since there are characteristics that makes them unique. Which involves the legal basis that contains them, the moment in which the courts are constituted, the standards that these apply, the type of resolutions that are issued, the instances that they possess, etc.
\end{abstract}

\footnotetext{
Magíster y Doctor en Derecho, abogado en ejercicio, socio del Estudio que lleva su nombre; profesor principal en la Pontificia Universidad Católica del Perú y en la Universidad Femenina del Sagrado Corazón. Decano de la Facultad de Derecho de la Universidad Católica San Pablo de Arequipa. Miembro de Número de la Academia Peruana de Derecho. Director de las colecciones Biblioteca de Arbitraje y Biblioteca de Derecho de su Estudio. www.castillofreyre.com
} 


\section{Breve introducción}

Para hablar sobre el arbitraje y los procesos que se siguen en la jurisdicción ordinaria, estimo conveniente realizar un análisis en paralelo acerca de cuáles son las semejanzas y diferencias entre uno y otros.

No es mi propósito, obviamente, agotar el tema en estas breves palabras, sino sólo delinear un marco general para abrir el debate.

\section{Por su base legal}

Tanto la jurisdicción ordinaria como el arbitraje están regulados por el artículo 62 de la Constitución, precepto que les brinda carácter jurisdiccional, conjuntamente con la jurisdicción militar.

No constituye objeto de este trabajo el analizar si la jurisdicción es una sola o si cabe hablar de tres tipos de jurisdicción; en otras palabras, no voy a ingresar al estudio de si la denominación otorgada por la Constitución, es o no correcta, pues resulta claro que independientemente de ello, el constituyente de 1993 quiso otorgar a ambas (la jurisdicción ordinaria y el arbitraje) igual jerarquía normativa, considerándolas -propiamente- jurisdicción.

En ese sentido, en lo que respecta a su base legal, el arbitraje y la jurisdicción ordinaria no se distinguen, más bien se asemejan.

\section{Por su origen}

Para recurrir al arbitraje, es claro que se requiere la existencia de un convenio arbitral, el mismo que podrá estar contenido en un contrato mayor celebrado entre las partes o podría consistir en un contrato especial.

Lo normal, como sabe, es que los convenios arbitrales constituyan una cláusula de un contrato que regule las condiciones entre las partes y que prevean que si ellas tuvieren alguna controversia, ésta se solucionará en el marco de un proceso arbitral.

Pero incluso en los supuestos en los cuales el arbitraje se acuerde con posterioridad al nacimiento del conflicto, el mismo tendrá origen contractual, así como lo tendrá en cualquiera de los supuestos contemplados por el artículo 13 de la Ley de Arbitraje. 
En cambio, es distinto el origen de los procesos judiciales, pues no es necesaria la existencia de una cláusula contractual relativa a la competencia de los tribunales ordinarios.

Si existiera tal cláusula, evidentemente su origen será contractual, pero con una salvedad y es que tal cláusula bien podría no existir y, aun así, los tribunales de la justicia ordinaria serían los competentes para conocer la controversia.

En lo que sí pueden disponer las partes es en el señalamiento de domicilios contractuales especiales, que otorguen competencia a jueces de determinada Corte Superior y eso sea lo que se acuerde en el contrato.

Independientemente de ello, la competencia de los tribunales ordinarios no nace de un contrato. Tiene naturaleza extracontractual.

\section{Por el momento de constitución de los tribunales}

En la jurisdicción ordinaria, los tribunales de justicia están constituidos con anterioridad al origen de las controversias surgidas entre los particulares.

Como todos sabemos, la Ley Orgánica del Poder Judicial y el Reglamento de Organización y Funciones del propio Poder Judicial (Resolución Administrativa n. . 226-2012-CE-PJ) establecen cuál es la conformación del aparato de justicia oficial del país, además de determinar la manera en que estarán conformados los tribunales y qué órganos serán los encargados de efectuar tales nombramientos. Esto, en adición a las funciones que otorga la Constitución Política del Perú al Consejo Nacional de la Magistratura.

Por lo demás, a menos que se trate de jurisdicciones con un número muy reducido de juzgados, el conocimiento de las causas estará determinado por la aleatoriedad, de modo tal que, dado que en nuestro tiempo ya no existen los turnos judiciales en materia civil, las partes no podrán escoger cuál es el juez que conocerá su causa, ya que la misma llegará a algún juzgado de manera aleatoria.

En cambio, en el caso del arbitraje, la situación es muy diferente, habida cuenta de que todo tribunal arbitral se constituye de manera particular para conocer la causa que será sometida a su competencia.

Es más, el procedimiento habitual de nombramiento de árbitros apunta en ese sentido, habida cuenta de que cada una de las partes 
(futuro demandante y futuro demandado), nombrará un árbitro; $y$, entre los dos, nombrarán a quien será presidente del tribunal arbitral.

Esto significa que los tribunales arbitrales no están preconstituidos a la controversia, ya que el inicio de esa controversia precede a la conformación de tales tribunales.

Ello también implica que los tribunales de la jurisdicción ordinaria existían y seguirán existiendo antes y después de concluida la controversia, a diferencia de los tribunales arbitrales que nacerán y se extinguirán con la misma. Sobre ese tema debemos hacer una salvedad, en lo que respecta a la ejecución del laudo y de la sentencia, ya que es regla general que en la justicia ordinaria los tribunales que resuelven no necesariamente serán los mismos que ejecuten las sentencias.

En el caso del arbitraje, resulta probable que el tribunal arbitral no cuente con facultades de ejecución, caso en el cual las partes tendrán que recurrir a la jurisdicción ordinaria para ejecutar el laudo¹.

También deberán recurrir a tales juzgados quienes venzan en un arbitraje, a pesar de que el tribunal arbitral tenga facultades de ejecución, si es que para llevarla adelante se requiera ordenar una ejecución forzosa, materia que escapa a las atribuciones de los tribunales arbitrales, los mismos que carecen de coertio.

Ello significa que en tanto los tribunales arbitrales cuenten con facultades de ejecución y no requieran ordenar medidas de fuerza, ellos mismos podrán ejecutar los laudos que hayan emitido.

\section{Por las normas a aplicar}

Los procesos judiciales están normados por el Código Procesal Civil del año 19932, con sus modificatorias. En cambio, los procesos arbitrales se rigen, en general, por la Ley de Arbitraje, Decreto Legislativo n. ${ }^{\circ} 1071$, del año 2008 y sus modificatorias.

Esto no significa que todos los arbitrajes se van a regular por esta ley, porque en algunos casos ella sólo resultará aplicable de manera suple-

\footnotetext{
1 Decreto Legislativo n. ${ }^{\circ} 1071$

«Artículo 8.- Competencia en la colaboración y control judicial (...)

3. Para la ejecución forzosa del laudo será competente el juez subespecializado en lo comercial o, en su defecto, el juez civil del lugar del arbitraje o el del lugar donde el laudo debe producir su eficacia».

2 Texto Único Ordenado del Código Procesal Civil - Resolución Ministerial n. . 010-93-JUS.
} 
toria, como ocurre en los supuestos de arbitraje y contratación estatal y de arbitraje en materia de expropiación, por citar dos ejemplos muy representativos.

Existe toda una discusión en el sentido de decir que las normas del Código Procesal Civil pueden aplicarse supletoriamente a la Ley de Arbitraje.

Tal discusión se centra en ver de qué manera las instituciones y figuras propias del proceso civil ordinario, son aplicables al arbitraje.

Por nuestra parte, no vemos inconveniente para que se proceda de esta forma, dado que muchas de las figuras e instituciones del proceso arbitral tienen sus raíces en el proceso civil y, sin duda, la doctrina que las respalda en materia procesal civil, resulta sólido sustento para las mismas en el arbitraje.

El ejemplo por excelencia es el relativo a la teoría de la prueba. Sobre este particular, podríamos preguntarnos si sería posible construir una teoría de la prueba para el arbitraje, siendo evidente que la respuesta negativa se impone. El Derecho no está para esfuerzos inútiles.

\section{Por su rigidez o flexibilidad}

De una simple lectura del Código Procesal Civil, queda claro que el grueso de sus disposiciones son de carácter imperativo, tanto en lo que respecta al diseño de los procedimientos que integran los procesos, como en lo referente a plazos y demás disposiciones.

Se puede decir que los diferentes modelos de proceso regulados por la ley procesal civil ordinaria, están signados por la rigidez. Se trata de un conjunto de procedimientos diseñados para ser seguidos de manera obligatoria, tanto por los jueces como por las partes en litigio.

La razón de ser de una disposición de esta característica se basa en que resultaría imposible para el Estado permitir a las partes que establezcan variantes dentro de estos modelos procedimentales, dada la existencia de los cientos de miles de procedimientos que se rigen por tales modelos en particular y por los varios miles de procesos de las mismas características que tiene a su cargo cada juez.

En ese sentido, resultaría impensable que tales procesos puedan incluir procedimientos y plazos distintos acordados por las partes, estimando que tal situación haría colapsar, de una vez por todas, los 
tribunales de la jurisdicción ordinaria. Ningún juez podría manejar un despacho judicial con estas variopintas características.

Distinta es la situación en los arbitrajes, pues no olvidemos que los árbitros son designados para conocer un proceso en específico; y una persona que se dedique al arbitraje, puede llevar a la vez, algunos pocos arbitrajes o, a lo mucho, en el mejor de los casos, algunas decenas de ellos; pero de ninguna manera la carga procesal del árbitro se podrá asemejar a la de un juez de la jurisdicción ordinaria. Siempre habrá varios abismos de distancia en los volúmenes de causas que conozca cada uno.

Son pues estas diferencias, las que permiten que en los arbitrajes las partes y los árbitros puedan diseñar características particulares para cada proceso, sin que ello constituya problema práctico alguno.

\section{Por las resoluciones que se emiten en el proceso}

Las resoluciones propias de los procesos judiciales son los decretos, los autos y las sentencias ${ }^{3}$ (resoluciones que ponen fin a la instancia).

En el caso de los arbitrajes, también hay decretos y autos, los mismos que llevan el nombre genérico de resoluciones, en tanto que el proceso arbitral concluye con una resolución denominada laudo, que es el equivalente a las sentencias de los procesos de la jurisdicción ordinaria. No obstante, pueden existir laudos parciales ${ }^{4}$.

3 Texto Único Ordenado del Código Procesal Civil

«Artículo 120.- Resoluciones

Los actos procesales a través de los cuales se impulsa o decide al interior del proceso o se pone fin a éste, pueden ser decretos, autos y sentencias.

Artículo 121.- Decretos, autos y sentencias

Mediante los decretos se impulsa el desarrollo del proceso, disponiendo actos procesales de simple trámite.

Mediante los autos el Juez resuelve la admisibilidad o el rechazo de la demanda o de la reconvención, el saneamiento, interrupción, conclusión y las formas de conclusión especial del proceso; el concesorio o denegatorio de los medios impugnatorios, la admisión, improcedencia o modificación de medidas cautelares y las demás decisiones que requieran motivación para su pronunciamiento.

Mediante la sentencia el Juez pone fin a la instancia o al proceso en definitiva, pronunciándose en decisión expresa, precisa y motivada sobre la cuestión controvertida declarando el derecho de las partes, o excepcionalmente sobre la validez de la relación procesal».

4 Decreto Legislativo n. ${ }^{\circ} 1071$

«Artículo 54.- Laudos

Salvo acuerdo en contrario de las partes, el tribunal arbitral decidirá la controversia en un solo laudo o en tantos laudos parciales como estime necesarios.» 


\section{Por el número de instancias}

Es garantía constitucional de la administración de justicia ordinaria y militar, la pluralidad de instancias, lo que significa que lo que se resuelva en primera instancia podrá ser, al menos, apelado a una segunda.

Los arbitrajes carecen de instancia plural. Esto implica que aquello que sea resuelto por el tribunal arbitral será inapelable.

El sistema de control de legalidad de los laudos arbitrales está dado por el denominado recurso de anulación del laudo, el mismo que se interpone ante la Sala Comercial del lugar donde haya sido expedido el laudo.

Tanto la Ley de Arbitraje de $1992^{5}$ como la de $1996^{6}$, contemplaban expresamente la posibilidad de que las partes pacten una segunda instancia arbitral, lo que significa que el laudo, en tales casos, podía ser objeto de recurso de apelación ante otro tribunal arbitral que se conforme de acuerdo a lo pactado por las partes.

En la práctica, dicha doble instancia no era moneda corriente y en mi experiencia profesional nunca tuve ocasión de asistir o conocer un caso en que las partes hubieren contemplado una segunda instancia en el arbitraje.

Es por esa falta de recurrencia, que la ley de arbitraje del 2008 ya no contempló la segunda instancia arbitral y el consiguiente recurso de apelación. Es más, el artículo 59 señala que el laudo es definitivo e inapelable. Sin embargo, esta última característica constituye, por su naturaleza, una norma de carácter dispositivo y no imperativo, razón por la cual cabe pacto en contrario.

5 Ley General de Arbitraje de 1992 - Decreto Ley n. 25935

«Artículo 58.- Es competente para conocer de la apelación ante el Poder Judicial del laudo de derecho la Sala Civil de la Corte Superior del lugar de la sede del arbitraje que hubiera conocido de la apelación a que se refiere el inciso 5 del artículo 15. De no ser ese el caso, es competente la Sala correspondiente al momento de presentar la apelación».

6 Ley General de Arbitraje de 1996 - Ley n. 26572

«Artículo 60.- Recurso de Apelación

Procede la interposición del recurso de apelación ante el Poder Judicial o ante una segunda instancia arbitral, cuando se hubiere pactado su admisibilidad en el convenio arbitral o si está previsto en el reglamento arbitral de la institución arbitral a la que las partes hubieran sometido su controversia. A falta de acuerdo expreso o en caso de duda, se entiende que las partes han pactado el recurso de apelación ante una segunda instancia arbitral. El recurso de apelación tiene por objeto la revisión del laudo respecto de la apreciación de los fundamentos de las partes, de la prueba y, en su caso, aplicación e interpretación del derecho, y se resuelve confirmando o revocando total o parcialmente el laudo. Contra los laudos de conciencia no procede recurso de apelación». 
En ese sentido, queda claro que el recurso de apelación no está prohibido; simplemente no está regulado.

De ello se deriva que, en aplicación del principio constitucional en el sentido de que aquello que no está prohibido ${ }^{7}$, está permitido, las partes tienen plena libertad para convenir una segunda instancia arbitral.

\section{Por la onerosidad}

No es que la administración de justicia ordinaria sea gratuita, dada la existencia de cédulas, tasas y otros pagos que la ley exige para litigar8.

Sin embargo, queda claro que tales costos, en verdad, resultan poco significativos en relación con los volúmenes controvertidos.

Es el Estado, por lo demás, quien solventa el mantenimiento del aparato de la justicia ordinaria. Sueldos de jueces y de todo el personal administrativo del Poder Judicial, locales, y todos los gastos que, en bienes y servicios, son necesarios para que pueda funcionar el aparato de la justicia ordinaria.

En cambio, en los arbitrajes son las partes las que solventan los honorarios de los árbitros y del secretario arbitral. Si se tratase de un arbitraje institucional, hablaríamos de honorarios de árbitros y de gastos administrativos del centro de arbitraje.

En el caso de los arbitrajes institucionales, los honorarios y gastos se rigen por tablas; y en el caso de los ad hoc, por lo que dispongan los propios árbitros a menos -claro está- que resulte aplicable al caso alguna tabla que el convenio arbitral hubiere contemplado, no obstante tratarse de un arbitraje ad hoc.

Los gastos arbitrales son mucho mayores que los judiciales, calculándose en función de porcentajes (usualmente no mayores al 3\%) de los montos controvertidos.

Por lo demás, en los procesos arbitrales, si las partes no cumplen con efectuar los pagos de honorarios, simplemente los tribunales estarán

\footnotetext{
7 «Artículo 2.- Toda persona tiene derecho: (...)

24. A la libertad y a la seguridad personales. En consecuencia: a. Nadie está obligado a hacer lo que la ley no manda, ni impedido de hacer lo que ella no prohíbe».

8 Ley n. ${ }^{\circ} 26846$ - Determinan principios que sustentan el pago de Tasas Judiciales y modifican el Código Procesal Civil y la Ley Orgánica del Poder Judicial.
} 
facultados para ordenar la suspensión y hasta el ulterior archivo del proceso.

En tal virtud, cuando se pacta un convenio arbitral, las partes son conscientes de que, si no disponen de tales recursos, el arbitraje se frustraría.

En realidad, son muchos más los aspectos en que resultan susceptibles de comparación los arbitrajes y los procesos de la jurisdicción ordinaria.

He querido, con estas palabras, hacer breve referencia a los más notorios.

Muchas gracias. 